\title{
Adsorption of Atmospheric Gases on Pu Surfaces
}

A. J. Nelson, K. S. Holliday, J. A. Stanford, W. K. Grant, R. G. Erler, P. G. Allen, W. McLean, P. Roussel

April 10, 2012

2012 MRS Spring Meeting San Francisco, CA, United States

April 9, 2012 through April 13, 2012 
This document was prepared as an account of work sponsored by an agency of the United States government. Neither the United States government nor Lawrence Livermore National Security, LLC, nor any of their employees makes any warranty, expressed or implied, or assumes any legal liability or responsibility for the accuracy, completeness, or usefulness of any information, apparatus, product, or process disclosed, or represents that its use would not infringe privately owned rights. Reference herein to any specific commercial product, process, or service by trade name, trademark, manufacturer, or otherwise does not necessarily constitute or imply its endorsement, recommendation, or favoring by the United States government or Lawrence Livermore National Security, LLC. The views and opinions of authors expressed herein do not necessarily state or reflect those of the United States government or Lawrence Livermore National Security, LLC, and shall not be used for advertising or product endorsement purposes. 


\title{
Adsorption of Atmospheric Gases on Pu Surfaces
}

\author{
A.J. Nelson ${ }^{1}$, K.S. Holliday ${ }^{1}$, J.A. Stanford ${ }^{1}$, W.K. Grant ${ }^{1}$, R.G. Erler ${ }^{1}$, P. Allen ${ }^{1}$, W. McLean ${ }^{1}$ \\ and P. Roussel ${ }^{2}$ \\ ${ }^{1}$ Lawrence Livermore National Laboratory, Livermore, CA 94550, U.S.A. \\ ${ }^{2}$ AWE Aldermaston, Reading, Berkshire RG7 4PR, U.K.
}

\begin{abstract}
Surface adsorption represents a competition between collision and scattering processes that depend on surface energy, surface structure and temperature. The surface reactivity of the actinides can add additional complexity due to radiological dissociation of the gas and electronic structure. Here we elucidate the chemical bonding of gas molecules adsorbed on Pu metal and oxide surfaces. Atmospheric gas reactions were studied at 190 and $300 \mathrm{~K}$ using X-ray photoelectron spectroscopy. Evolution of the $\mathrm{Pu} 4 \mathrm{f}$ and $\mathrm{O}$ 1s core-level states were studied as a function of gas dose rates to generate a set of Langmuir isotherms. Results show that the initial gas dose forms $\mathrm{Pu}_{2} \mathrm{O}_{3}$ on the $\mathrm{Pu}$ metal surface followed by the formation of $\mathrm{PuO}_{2}$ resulting in a layered oxide structure. This work represents the first steps in determining the activation energy for adsorption of various atmospheric gases on $\mathrm{Pu}$.
\end{abstract}

\section{INTRODUCTION}

Understanding the surface dynamics of oxidation and reduction reactions on actinide materials is important to the continued development of advanced nuclear fuel technologies. Knowledge of the surface reactions with various environmental and atmospheric agents, and the subsequent degradation processes, over a wide range of temperatures are vitally important. Past reviews of the oxidation of actinide elements [1-4] illuminate the ambient reaction mechanisms and growth kinetics at atmospheric and reduced pressures.

The dynamics of gas-surface interactions depend on the energy of the gaseous species, the temperature, and the atomic structure of the solid surface. Radiological dissociation of the gaseous species and the electronic structure of actinide surfaces further enhance surface reactivity. [5] Here we investigate the chemical bonding of gas molecules adsorbed on Pu metal and oxide surfaces at $190 \mathrm{~K}$ and $300 \mathrm{~K}$ using X-ray photoelectron spectroscopy (XPS). The evolution of the $\mathrm{Pu} 4 \mathrm{f}$ and $\mathrm{O}$ 1s core-levels as a function of gas dose rates provides a comprehensive characterization of the oxide growth.

\section{EXPERIMENT}

Gas dosing of the electropolished gallium stabilized $\delta$-phase $\mathrm{Pu}$ was performed in the UHV chamber at $1 \times 10^{-6}$ torr after Ar-ion sputter etching to remove the native oxide. Sputter cleaning was accomplished with $4.5 \mathrm{kV} \mathrm{Ar}^{+}$rastered over a broad $7 \times 7 \mathrm{~mm}$ area giving a sputter etch rate of $\approx 0.1 \mathrm{~nm} / \mathrm{min}$. XPS experiments were subsequently performed using a Physical Electronics 5400 system with an $\mathrm{Al} \mathrm{K} \alpha$ radiation $(1486.6 \mathrm{eV})$ source for excitation and a hemispherical analyzer. XPS spectra were acquired in normal emission geometry. The pass 
energy was $22.35 \mathrm{eV}$ giving an energy resolution of $0.5 \mathrm{eV}$ that when combined with the natural $\mathrm{Al} \mathrm{K} \alpha$ line width gives a resolvable XPS peak width of approximately $1.5 \mathrm{eV} \mathrm{FWHM.}$

Deconvolution of non-resolved peaks was accomplished using Multipak 9.2 (PHI) curve fitting routines with asymmetric line-shape for the metal and Gaussian-Lorentzian line-shape for the oxides, all with a Shirley background. The collected data were referenced to an energy scale with binding energies for $\mathrm{Cu} 2 \mathrm{p}_{3 / 2}$ at $932.72 \pm 0.05 \mathrm{eV}$ and $\mathrm{Au} 4 \mathrm{f}_{7 / 2}$ at $84.01 \pm 0.05 \mathrm{eV}$.

\section{RESULTS AND DISCUSSION}

Figure 1 shows the evolution of the $\mathrm{Pu} 4 \mathrm{f}_{7 / 2,5 / 2}$ spin-orbit pair as a function of $\mathrm{O}_{2}$ dosing at a substrate temperature of $300 \mathrm{~K}$. The $\mathrm{Pu} 4 \mathrm{f}$ curve fits show three components due to $\mathrm{Pu}^{0}$ $(422.0 \mathrm{eV}), \mathrm{Pu}^{3+}(424.6 \mathrm{eV})$ and $\mathrm{Pu}^{4+}(426.2 \mathrm{eV})$. The area of each $\mathrm{Pu} 4 \mathrm{f}_{7 / 2}$ component was normalized to the total $\mathrm{Pu} 4 \mathrm{f}_{7 / 2}$ area and plotted as a function of $\mathrm{O}_{2}$ dose as shown in Fig. 2. These results show that at $300 \mathrm{~K}$ the initial gas dose forms $\mathrm{Pu}_{2} \mathrm{O}_{3}$ on the $\mathrm{Pu}$ metal surface followed by the formation of $\mathrm{PuO}_{2}$ resulting in a layered oxide structure. Note however that both figures show incomplete $\mathrm{PuO}_{2}$ coverage of the $\mathrm{Pu}_{2} \mathrm{O}_{3}$ on the $\mathrm{Pu}$ metal surface.

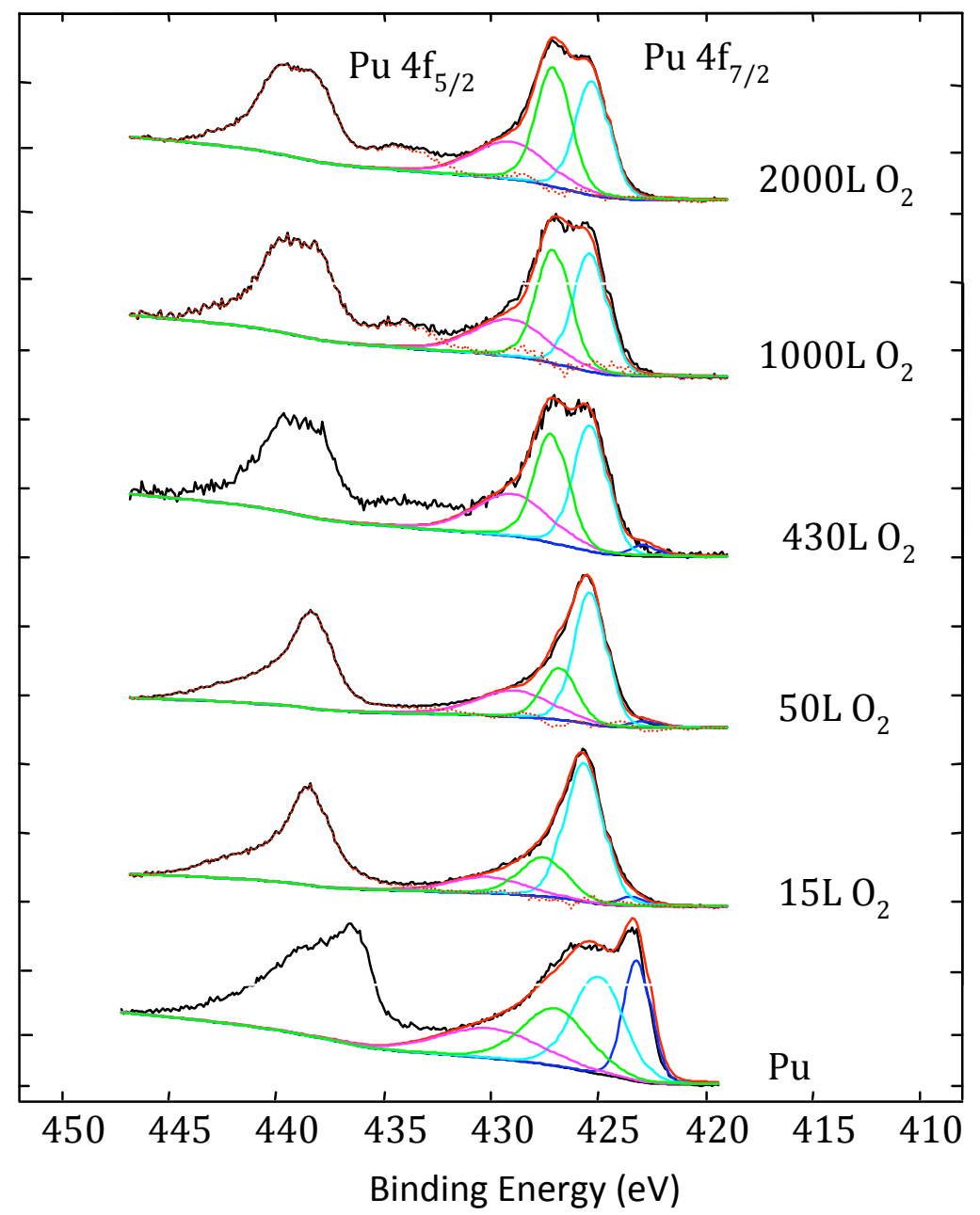

Figure 1. Select $\mathrm{Pu} 4 \mathrm{f}_{7 / 2,5 / 2}$ spectra for $\mathrm{O}_{2}$ dosing at $300 \mathrm{~K}$ showing the $\mathrm{Pu}^{0}, \mathrm{Pu}^{3+}$ and $\mathrm{Pu}^{4+}$ Gaussian-Lorentzian components. 
Competition between oxide growth and auto-reduction of $\mathrm{Pu}^{4+}$ to $\mathrm{Pu}^{3+}$ in vacuum was not easily overcome at ambient temperature. Cooling the Pu substrate during gas dosing was found to slow the $\mathrm{Pu}^{4+}$ to $\mathrm{Pu}^{3+}$ reduction in ultrahigh vacuum.

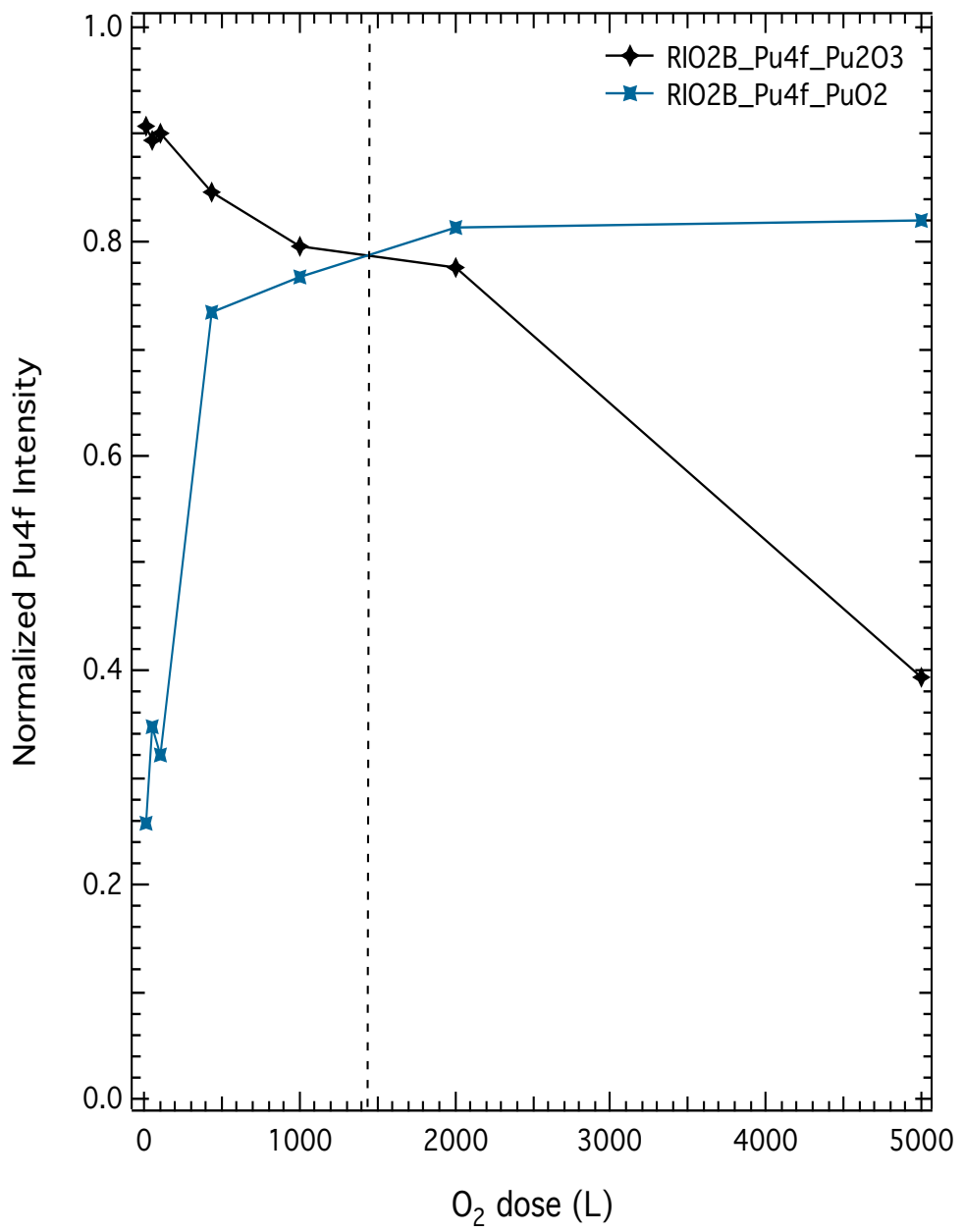

Figure 2. Pu oxide growth profile at $300 \mathrm{~K}$ based on normalized areas of the $\mathrm{Pu}^{0}, \mathrm{Pu}^{3+}$ and $\mathrm{Pu}^{4+}$ components from Figure 1.

The evolution of the $\mathrm{Pu}^{0}, \mathrm{Pu}^{3+}$ and $\mathrm{Pu}^{4+} 4 f$ components as a function of $\mathrm{O}_{2}$ dosing at a substrate temperature of $193 \mathrm{~K}$ are presented in Figure 3. Each component was again normalized to the total $\mathrm{Pu} 4 \mathrm{f}_{7 / 2}$ area and plotted as a function of $\mathrm{O}_{2}$ dose (Fig. 4). Again we note incomplete $\mathrm{PuO}_{2}$ coverage of the $\mathrm{Pu}_{2} \mathrm{O}_{3}$ on the $\mathrm{Pu}$ metal surface. Angle-resolved measurements did not indicate the presence of $\mathrm{PuO}_{2}$ islands leading us to invoke the Cabrera-Mott theory [6, 7] to describe the oxidation of Pu metal at these low temperatures. Typical thermal diffusion mechanisms are quenched at these lower temperatures, so Cabrera and Mott theorized that cation or anion diffusion occurs under the influence of a potential across the growing oxide film. Specifically, an electronic equilibrium exists between the gas-oxide and metal-oxide interfaces that results in field assisted diffusion of oxygen anions across these interfaces at low 
temperature. [8] These initial analyses of the kinetic and equilibrium data assume surface energetic heterogeneity of the polycrystalline Pu surface.

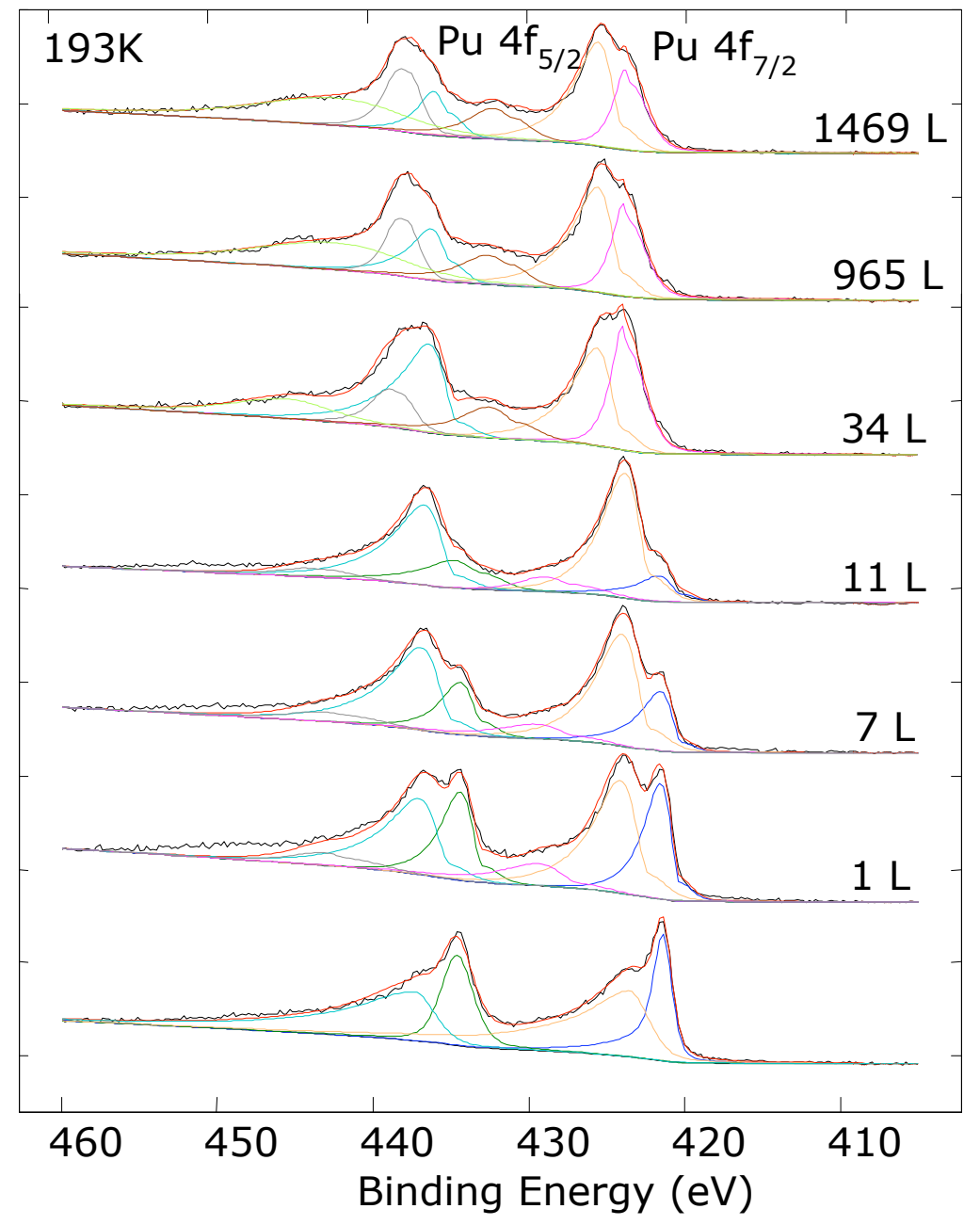

Figure 3. Select $\mathrm{Pu} 4 \mathrm{f}_{7 / 2,5 / 2}$ spectra for $\mathrm{O}_{2}$ dosing at $193 \mathrm{~K}$ showing the evolution of the $\mathrm{Pu}^{0}, \mathrm{Pu}^{3+}$ and $\mathrm{Pu}^{4+}$ components.

\section{CONCLUSIONS}

XPS was used to observe the growth of a $\mathrm{PuO}_{2} / \mathrm{Pu}_{2} \mathrm{O}_{3} / \mathrm{Pu}$ layered structure at $190 \mathrm{~K}$ and $300 \mathrm{~K}$. The two equilibrium adsorption isotherms at $190 \mathrm{~K}$ and $300 \mathrm{~K}$ are the first steps in determining the activation energy for adsorption of various atmospheric gases on Pu. Further experiments are essential to determine the initial sticking probability and the kinetics of gas adsorption on actinide surfaces.

\section{ACKNOWLEDGMENTS}

This work performed under the auspices of the U.S. Department of Energy by Lawrence Livermore National Laboratory under Contract DE-AC52-07NA27344. 


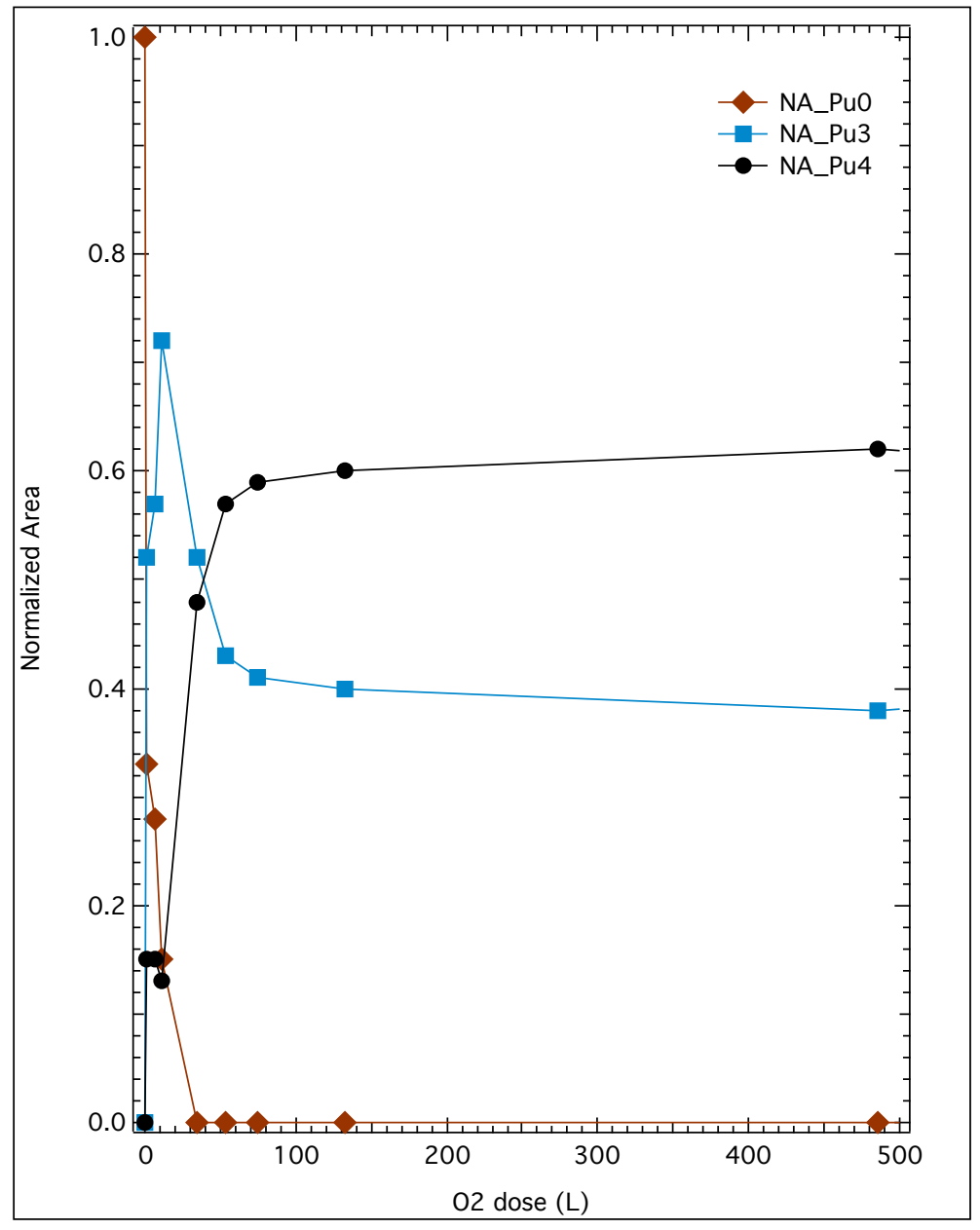

Figure 4. $\mathrm{Pu}$ oxide growth profile at $193 \mathrm{~K}$ based on normalized areas of the $\mathrm{Pu}^{0}, \mathrm{Pu}^{3+}$ and $\mathrm{Pu}^{4+}$ components from Figure 3.

\section{REFERENCES}

1. C.A. Colmenares, Prog. Solid State Chem. 15, 257 (1984)

2. J.M. Haschke, J.C. Allen, L.A. Morales, Los Alamos Sci. 26, 253 (2000)

3. M.T. Butterfield, T. Durakiewicz, E. Guziewicz, J.J. Joyce, A.J. Arko, K.S. Graham, D.P. Moore, L.A. Morales, Surf. Sci. 571, 74 (2004)

4. H.G. Garcia Flores, P. Roussel, D.P. Moore, D.L. Pugmire, Surf. Sci. 605, 314 (2011)

5. T. Almeida, L.E. Cox, J.W. Ward, J.R. Naegele, Surf. Sci. 287/288, 141 (1993)

6. N. Cabrera, N.F. Mott, Rept. Progr. Phys. 12, 163 (1949)

7. F.P. Fehlner, N.F. Mott, Oxidation of Metals 2, 59 (1970)

8. C. Ocal, S. Ferrer, N. Garcia, Surf. Sci. 163, 335 (1985) 